\title{
Thermal and kinetic analysis of pure and contaminated ionic liquid: 1-butyl-2.3-dimethylimidazolium chloride (BDMIMCl)
}

\author{
Ayyaz Muhammad ${ }^{1,2}$ \\ ${ }^{1}$ King Abdul Aziz University, Department of Chemical \& Materials Engineering, P.O. Box 80200, Jeddah, Saudi Arabia \\ ${ }^{2}$ University of the Punjab, Institute of Chemical Engineering \& Technology, Lahore-54590, Pakistan \\ "Corresponding author: e-mail: atozmoon@yahoo.com,anawaz@kau.edu.sa
}

\begin{abstract}
In this research work, thermal decomposition and kinetic analysis of pure and contaminated imidazolium based ionic liquid (IL) has been investigated. As thermal decomposition and kinetics evaluation plays a pivotal role in effective process design. Therefore, thermal stability of pure 1-butyl-2,3-dimethylimidazolium chloride (BDMIM$\mathrm{Cl}$ ) was found to be higher than the sample of IL with the addition of $20 \%$ (wt.) $\mathrm{NH} 4 \mathrm{Cl}$ as an impurity. The activation energy of thermal degradation of IL and other kinetic parameters were determined using Coats Redfern method. The activation energy for pure IL was reduced in the presence of $\mathrm{NH} 4 \mathrm{Cl}$ as contaminant i.e., from 58.7 $\mathrm{kJ} / \mathrm{mol}$ to $46.4 \mathrm{~kJ} / \mathrm{mol}$.
\end{abstract}

Keywords: ionic liquid, thermal stability, kinetic analysis, activation energy.

\section{INTRODUCTION}

Ionic liquids (ILs) are considered to be salts which are 'liquid' below $100^{\circ} \mathrm{C}$ and made up solely of cations and anions ${ }^{1-2}$. These ILs possess a number of extraordinary properties of great interest, for instance, high thermal stability ${ }^{3}$, wide liquidus range ${ }^{4}$ i.e., -96 to $400^{\circ} \mathrm{C}$, wide electrochemical window ${ }^{5}$ and negligible vapor pressure ${ }^{6}$. The unique properties of ILs can also be exploited for their effective use in separation processes, catalysis, super capacitors and photovoltaic ${ }^{7}$. In spite of numerous advantages of ILs, this is worrying to know that far only few ILs have been manufactured and utilized on commercial scale. One of the reasons is the lack of information about thermal behavior of these ionic liquids ${ }^{8}$. Moreover, the investigation of thermal properties of ILs is imperative for design and evaluation, to set the feasible temperature operating range in a chemical process and to estimate heating and cooling requirements as well as heat-storage capacity. Thermal stability of imidazolium based ILs was studied at constant heating rate of $10^{\circ} \mathrm{C} / \mathrm{min}$ and $20^{\circ} \mathrm{C} /$ min which revealed that different heating rates did not affect thermal stability to a significant extent'. Thermal stability and kinetics of thermal decomposition of few ILs were investigated in the temperature range ${ }^{10}$ of $150^{\circ} \mathrm{C}$ to $200^{\circ} \mathrm{C}$. Ionic liquids with phosphate anions have low thermal stability as compared to those having triflate anions ${ }^{11}$. The kinetics for thermal decomposition of Imidazolium based ILs, with respect to isothermal and ramp experiments, were explored by some researchers ${ }^{12}$. The kinetics for constant heating rate (ramp runs) was evaluated using Friedman's iso-conversional method whereas a pseudo zero order kinetics was attributed to the linear nature of the decomposition data over a conversion rate of $0<\alpha<0.81$. Recently, a theoretical approach called Group Contribution Method (GCM) has been introduced to predict thermal decomposition temperatures of the ionic liquids ${ }^{13}$. The complex nature of thermal degradation of solids and non-volatile liquids has been investigated through various methods to explore the decomposition kinetics. However, most of the researchers have studied the decomposition kinetics of ILs using a specific temperature range ignoring the thermal behavior of the material in rest of the tempera- ture range ${ }^{4,10-11}$. The activation energies determined for a specific temperature range does not correspond to the entire thermal event, therefore, there is a need to investigate the kinetic parameters for full temperature range of thermo-gravimetric analysis. Friedman's method is used to find the kinetic parameters for the nonisothermal experiments, however, in this method, one sample must be subjected to multiple TGA ramp runs (e.g. $10^{\circ} \mathrm{C} / \mathrm{min}, 15^{\circ} \mathrm{C} / \mathrm{min}, 20^{\circ} \mathrm{C} / \mathrm{min}$ etc.) which leads to its limitation for the determination of kinetic parameters in the single ramp run ${ }^{14-15}$. Similarly, the methods of Kissinger, Freeman-Carroll, Flynn-Wall-Ozowa (FWO) and Coats Redfern (CR) are used for the kinetic studies of non-isothermal thermo-gravimetric analysis, however, the Coats Redfern method has been widely used.

The present work describes the kinetic study of 1-butyl-2.3-dimethylimidazolium chloride (BDMIMCl) with its thermal decomposition in thermogravimetric analysis. As the standard methods for the preparation of ILs may lead to the presence of halide impurities which can severely affect the catalysis reactions, therefore, thermal stability and kinetics of thermal decomposition of IL with the addition of $20 \% \mathrm{NH}_{4} \mathrm{Cl}$ as contaminant has also been studied. The kinetic parameters were determined using Coats Redfern method

\section{MATERIAL AND METHODS}

1-butyl-2.3-dimethylimidazolium chloride (BDMIMCl) (CAS No. 98892-75-2) and Ammonium Chloride (CAS. No. 12125-02-9) with $99.99 \%$ purity were purchased from Merck (Germany). The purity of IL sample was above $99.99 \%$ and was subjected to vacuum drying for 48 hours to remove any traces of moisture prior to their use. BDMIMCl was contaminated with $20 \%$ (wt.) ammonium chloride $\left(\mathrm{NH}_{4} \mathrm{Cl}\right)$. Thermogravimetric Analysis was performed using SDT Q600 (TA Instruments, USA) at a temperature ramp of $10^{\circ} \mathrm{C} / \mathrm{min}$ under nitrogen purge gas at $100 \mathrm{ml} / \mathrm{min}$. Thermogravimetric data was used to study the kinetics analysis of ILs using Coats Redfern Method through Ginstlinge-Brounshtein equation. 


\section{RESULTS AND DISCUSSIONS}

\section{Thermal Decomposition}

The onset and final decomposition temperatures of pure and contaminated IL are presented in Table 1 . The onset temperature $\left(\mathrm{T}_{\text {onset }}\right)$ is the point of intersection of the baseline weight and the tangent of the weight vs temperature curve as decomposition occurs whereas $T_{f}$ is the final decomposition temperature ${ }^{9}$. It is obvious from the high onset and final decomposition temperatures and of pure $\left(267\right.$ and $\left.360^{\circ} \mathrm{C}\right)$ and contaminated samples $(267$ and $360^{\circ} \mathrm{C}$ ), that ILs are thermally stable. The onset temperature of three imidazolium based ILs \{i.e., 1-butyl-3-methylimidazolium chloride (BMIM-Cl) and 1-hexyl-3-methylimidazolium tetraflouroborate $\left(\mathrm{HMIMBF}_{4}\right)$ and 1-hexyl-3-methylimidazolium hexaflourophosphate $\left.\left(\mathrm{HMIMPF}_{6}\right)\right\}^{\mathbf{1 6}}$ is also presented in Table 1 . It is observed that the thermal stability of imidazolium based ILs depends more on the anion as compared to cation and found to be in decreasing order of $\mathrm{PF}_{6}>\mathrm{BF}_{4}>\mathrm{Cl}$, however, the effect of methyl substitution on cation was also found to be significant as $\mathrm{T}_{\text {onset }}$ of $\mathrm{BDMIMCl}$ $\left(267^{\circ} \mathrm{C}\right)$ is higher than BMIM-Cl $\left(125.1^{\circ} \mathrm{C}\right)$.

\section{Coats Redfern Method of Kinetic Analysis}

The kinetic evaluation of the studied samples is performed using Coats Redfern Method through Ginstlinge-Brounshtein equation (three-dimentional diffusion) to evaluate the kinetic parameters. In decomposition kinetic studies, various researchers have used both iso-conventional and discrimination methods, as per their findings by comparing the activation energies, it is quite justified to use either Flynn-Wall-Ozowa (FWO) or Coats Redfern (CR) models to estimate the kinetic mechanism of different materials by thermal degradation ${ }^{19-23}$. In non-isothermal kinetic studies, the relation for linear temperature increase with time is given as follows:

$\mathrm{T}=\mathrm{T}_{\mathrm{o}}+\beta \mathrm{t}$

Where $\beta$ is the constant heating rate, $T_{0}$ is the initial temperature and $\mathrm{t}$ is the time. The conversion fraction is given as under;

$\alpha=\frac{\mathrm{m}_{\mathrm{o}}-\mathrm{m}_{\mathrm{t}}}{\mathrm{m}_{\mathrm{o}}-\mathrm{m}_{\infty}}$

Where $m_{o}$ is the initial sample mass, $m_{t}$ is the sample mass at certain time and $\mathrm{m}_{\infty}$ is the mass of sample at infinite time (i.e. $\mathrm{m}_{\infty}=0$ ). The rate of reaction is therefore given as follows;

Table 1. Thermal decomposition characteristics such as onset/final decomposition temperatures and kinetic parameters of pure and contaminated IL

\begin{tabular}{|l|c|c|c|c|c|c|}
\hline Ionic liquids (ILs) & \multicolumn{1}{|c|}{$\begin{array}{c}\mathrm{T}_{\text {onset }} \\
{\left[{ }^{\circ} \mathrm{C}\right]}\end{array}$} & $\mathrm{T}_{\mathrm{f}}\left[{ }^{\circ} \mathrm{C}\right]$ & $\mathrm{E}_{\mathrm{a}}[\mathrm{kJ} / \mathrm{mol}]$ & $\begin{array}{c}\mathrm{A} \\
{\left[\mathrm{sec}^{-1}\right]}\end{array}$ & $\mathrm{R}^{2}$ \\
\hline $\mathrm{BDMIM}-\mathrm{Cl}$ (pure) & 267 & $\begin{array}{c}{ }^{*} 125.1 \mathrm{BMIM}^{*} \mathrm{Cl} \\
{ }^{*} 348.1 \mathrm{HMIMBF}_{4}\end{array}$ & 360 & 58.688 & 0.779 & 0.959 \\
\hline $\mathrm{BDMIM}-\mathrm{Cl}+20 \% \mathrm{NH}_{4} \mathrm{Cl}$ & 245 & & 350 & 46.350 & 0.083 & 0.995 \\
\hline
\end{tabular}

${ }^{*}$ Reference 16

Thermal decomposition curve of pure and contaminated 1-butyl-2,3-dimethylimidazolium chloride (BDMIM$-\mathrm{Cl}$ ) is shown in Figure 1. It is observed that the presence of impurity (addition of $20 \% \mathrm{NH}_{4} \mathrm{Cl}$ ) in IL decreases its thermal stability due to the difference of interactive forces at molecular level of pure and contaminated materials. It is also pertinent to mention that initially IL decomposes very slowly i.e., $10 \%$ wt. loss at $250^{\circ} \mathrm{C}$, however, rapid and significant mass loss (i.e., 90\% wt.) occurs within next $110^{\circ} \mathrm{C}$. The onset of decomposition temperatures of the investigated IL is quite promising and consistent with the data presented by other authors on isothermal stability of imidazolium based ILs ${ }^{12,17,18}$.

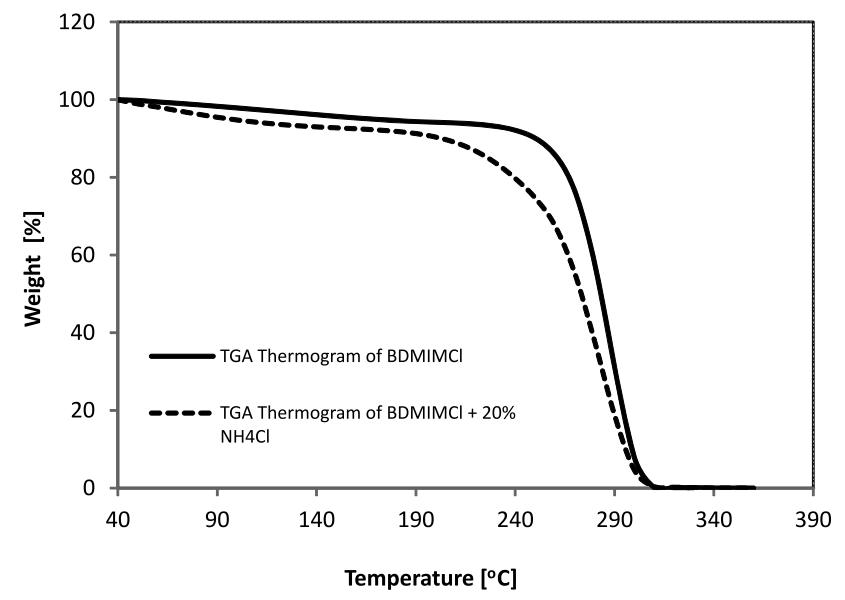

Figure 1. Thermogram of pure and contaminated 1-butyl2-3-dimethyl imidazolium chloride (BDMIM-Cl) $\frac{d \alpha}{d t}=k f(\alpha)$

Comparing equation (1) and (3) gives:

$\frac{\mathrm{d} \alpha}{\mathrm{dT}}=\frac{d \alpha}{d t} X \frac{d t}{d T}=\frac{\mathrm{k} f(\alpha)}{\beta}$

Where $\mathrm{k}$ is the rate coefficient which can be described by the Arrhenius equation as follows:

$k=A \exp \frac{-E}{R T}$

In case of a linear heating rate $\beta$, equation (3) and equation (5) can be combined as follows:

$\frac{\mathrm{d} \alpha}{f(\alpha)}=\frac{A}{\beta} \exp \left(-\frac{E}{R T}\right) \mathrm{dT}$

The integration of equation (6) by Coats Redfern method formulates the following relation:

$\ln \left[\frac{\mathrm{g}(\alpha)}{\mathrm{T}^{2}}\right]=\ln \left(\frac{A R}{\beta E}\right)-\frac{E}{R T}$

where $\mathrm{A}$ is the apparent pre-exponential factor, $\mathrm{R}$ is the universal gas constant $(8.314 \mathrm{~J} / \mathrm{mol} . \mathrm{K}), \beta$ is the constant heating rate $(\mathrm{K} / \mathrm{min}), \mathrm{E}$ is the apparent activation energy $(\mathrm{kJ} / \mathrm{mol} . \mathrm{K})$ and $\mathrm{T}$ is the absolute temperature in $\mathrm{K}$ and;

$\mathrm{g}(\alpha)=\int_{0}^{\alpha} \frac{\mathrm{d} \alpha}{f(\alpha)}$

where $f(\alpha)$ is a function of the degradation process and function $g(\alpha)$ depends on the reaction mechanism. Sub- 


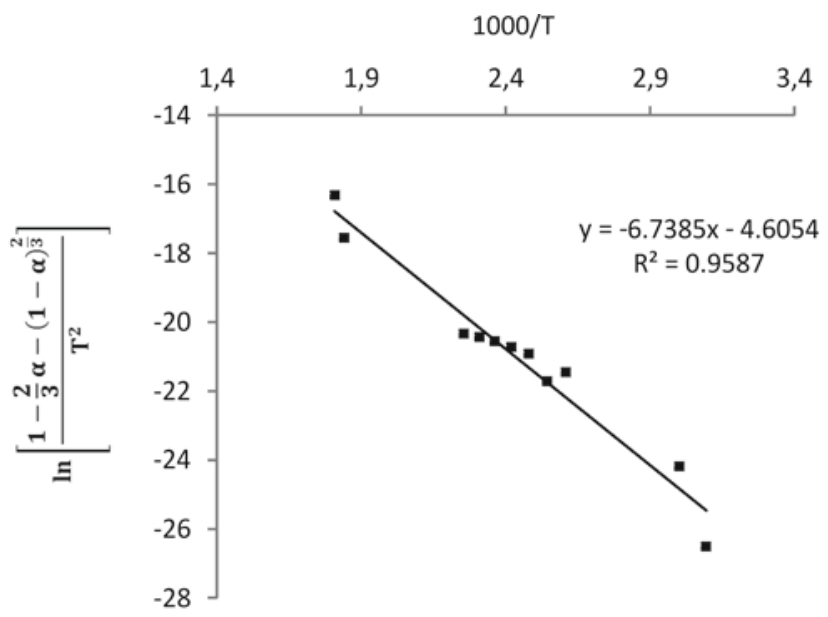

Figure 2. Plot of $\ln [g(\alpha) / T 2]$ vs 1000/T for pure 1-butyl-2-3-dimethylimidazolium chloride (BDMIM-Cl)

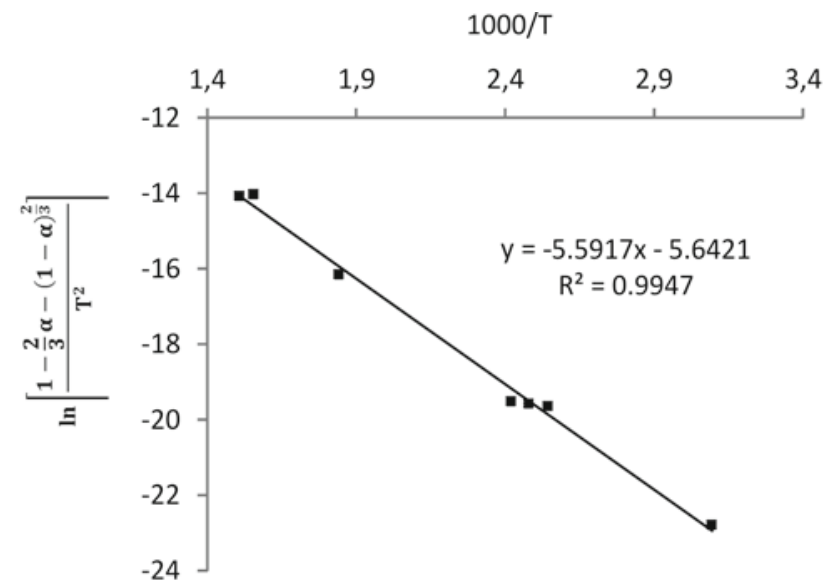

Figure 3. Plot of $\ln [g(\alpha) / T 2]$ vs 1000/T for 1-butyl-2-3-dimethylimidazolium chloride (BDMIM-Cl) $+20 \% \mathrm{NH} 4 \mathrm{Cl}$

stituting $\mathrm{g}(\alpha)=1-\frac{2}{3} \alpha-(1-\alpha)^{\frac{2}{3}}$ a plot of the left hand side of equation $(7)^{3}$ versus $1 / \mathrm{T}$ gives a straight line with slope equal to $-\mathrm{E} / \mathrm{R}$ and $\mathrm{y}$-intercept equal to $\ln (\mathrm{AR} / \beta \mathrm{E})$. The pre-exponential factor ' $A$ ' can be calculated from the intercept and the activation energy can be calculated from the slope of the straight line produced. The values of kinetic parameters such as activation energies $\left(E_{a}\right)$, pre-exponential factor $(A)$ and the corresponding values of regression coefficient $(\mathrm{R})$ are given in Table 1 . The presence of $\mathrm{NH}_{4} \mathrm{Cl}$ as contaminant reduced the activation energy of BDMIM-Cl to $46.35 \mathrm{KJ} / \mathrm{mol}$. The regression analysis was performed after fitting the data curves by least square method for the studied pure and contaminated IL as shown in Figures 2 and 3 respectively. A good mathematical adjust of experimental points to the straight line equation as represented by the values of correlation coefficients i.e., $\mathrm{R}^{2} \geq 0.997$ which indicates that the Coats Redfern model adjust to the kinetic decomposition study for the studied IL sample.

\section{CONCLUSIONS}

The determination of the thermal decomposition temperature and kinetics of decomposition is of paramount importance for the effective process design and precise development of contacting equipment. Thermal stability study of ILs is also necessary for the investigation of their high temperature applications. Moreover, the investigation of physical and thermodynamic properties is vital for equipment sizing and heat storage capacity of the ionic liquids. In this study, step tangent method has been employed to study the thermal stability of imidazolium based IL. The addition of contaminant in IL such as $\mathrm{NH}_{4} \mathrm{CI}$ led to lower the thermal stability as the presence of halides reduces the thermal stability of ILs. The decrease activation energy of IL in the presence of contaminant could be due to the presence of the halide ions contributed by the ionization of $\mathrm{NH}_{4} \mathrm{Cl}$ contaminant.

\section{ACKNOWLEDGEMENT}

This work was funded by the Deanship of Scientific Research (DSR), King Abdulaziz University, Jeddah, under grant No. 135-027-D1434. The authors, therefore, acknowledge with thanks DSR technical and financial support.

\section{LITERATURE CITED}

1. Endres, F., MacFarlane, D. \& Abbott, A. (2008). Electrodeposition from Ionic Liquids. ( $1^{\text {st }}$ ed.). Germany: Wiley-VCH. 2. Fredlake, C.P., Crosthwaite, J.M., Hert, D.G., Aki, S.N.V.K. \& Brennecke, J.F. (2004). Thermophysical Properties of Imidazolium-Based Ionic Liquids. J. Chem. Eng. Data, 49, 954-964. DOI: $10.1021 /$ je034261a.

3. Hao, Y., Peng, J., Hu, S., Zhai, J. \& Li, M. (2010). Thermal decomposition of allyl-imidazolium-based ionic liquid studied by TGA-MS analysis and DFT calculations. Therm. Acta, 501, 78-83. DOI: 10.1016/j.tca.2010.01.013.

4. Seddon, K.R., Stark, A. \& María-José, T. (2000). Influence of chloride, water and organic solvents on the physical properties of ionic liquids. Pure \& Appl. Chem. 72, 2275-2287. DOI: $10.1351 /$ pac200072122275.

5. Hagiwara, R. \& Ito, Y. (2000). Room temperature ionic liquids of alkyl imidazolium cations and fluoro anions. J. Fluorine Chem. 105, 221-227. DOI: 10.1016/S0022-1139(99)00267-5. 6. Stevanovic, S. \& Gomes, M.F.C. (2013). Solubility of carbon dioxide, nitrous oxide, ethane, and nitrogen in 1-butyl-1-methylpyrrolidinium and trihexyl(tetradecyl)phosphonium tris(pentafluoroethyl)trifluorophosphate (eFAP) ionic liquids. J. Chem. Therm. 59, 65-71. DOI: 10.1016/j.jct.2012.11.010.

7. Ngo, H.L., LeCompte, K., Hargens, L. \& McEwen, A. B. (2000). Thermal properties of imidazolium ionic liquids. Therm. Acta. No. 357-358, 97-102. DOI: 10.1016/S00406031(00)00373-7.

8. Joglekar, H.G., Rahman, I. \& Kulkarni, B.D. (2007). The Path Ahead for Ionic Liquids. Chem. Eng. Technol., 30, 819-828. DOI: 10.1002/ceat.200600287.

9. Muhammad, A., Abdul Mutalib, M.I., Wilfred, C.D., Murugesan, T. \& Shafeeq, A. (2008). Thermophysical properties of 1-hexyl-3-methyl imidazolium based ionic liquids with tetrafluoroborate, hexafluorophosphate and bis(trifluoromethylsulfonyl)imide anions. J. Chem. Therm. 40, 1433-1438. DOI: $10.1016 /$ j.jct.2008.04.016.

10. Kamavaram, V. \& Reddy, R.G. (2008). Thermal stabilities of di-alkylimidazolium chloride ionic liquids. Int. J. Therm. Sci. 47, 773-777. DOI: 10.1016/j.ijthermalsci.2007.06.012.

11. Kosmulski, M., Gustafsson, J. \& Rosenholm, J.B. (2004). Thermal stability of low temperature ionic liquids revisited. Therm. Acta. 412, 47-53. DOI: 10.1016/j.tca.2003.08.022.

12. Fox, D.M., Gilman, J.W., De Long, H.C. \& Trulove, P.C. (2005). TGA decomposition kinetics of 1-butyl-2,3-dimethylimidazoliumtetrafluoroborate and the thermal effects of contaminants. J. Chem. Therm. 37, 900-905. DOI: 10.1016/j. jct.2005.04.020. 
13. Lazzús, J.A. (2012). A group contribution method to predict the thermal decomposition temperature of ionic liquids. J. Mol. Liquids 168, 87-93. DOI: 10.1016/j.molliq.2012.01.011. 14. Jankovic', B., Mentus, S. \& Jankovic', M. (2008). A kinetic study of the thermal decomposition process of potassium meta bisulfite: Estimation of distributed reactivity model. J. Phys. Chem. Solids 69, 1923-1933. DOI: 10.1016/j.jpcs.2008.01.013. 15. Lu, C., Song, W. \& Lin, W. (2009). Kinetics of biomass catalytic pyrolysis. Biotechn. Adv. 27, 583-587. DOI: 10.1016/j. biotechadv.2009.04.014.

16. Zhang, Z. \& Reddy, R.G. (2002). Thermal stability of ionic liquids, TMS annual meeting.

17. Tonbul, Y. \& Yurdakoc, K. (2001). Thermogravimetric Investigation of the Dehydration Kinetics of KSF, K10 and Turkish Bentonite. Turk J. Chem. 25, 333-339. DOI: 10.1080/22243682.2013.871210.

18. Kroon, M.C., Buijs, W., Peters, C.J. \& Geert-Jan, W. (2007). Quantum chemical aided prediction of the thermal decomposition mechanisms and temperatures of ionic liquids. Therm. Acta 465, 40-47. DOI: 10.1016/j.tca.2007.09.003.

19. Manikandan, G., Rajarajan, G., Jayabharathi, J. \& Thanikachalam, V. (2011). Structural effects and thermal decomposition kinetics of chalcones under non-isothermal conditions. A. J. Chem., In Press. DOI: 10.1016/j. arabjc.2011.06.029.

20. Yao, F., Wu, Q., Lei, Y., Guo, W. \& Xu, Y. (2008). Thermal decomposition kinetics of natural fibers: Activation energy with dynamic thermogravimetric analysi. Polym. Deg. Stabil. 93, 90-98. DOI: 10.1016/j. polymdegradstab.2007.10.012.

21. Omrani, A. \& Hasankola, S.M.M. (2012). Kinetic study on solid state thermal degradation of epoxy nanocomposite containing Octasilane polyhedral oligomeric silsesquioxane. J. Non-Crystalline Sol. 358, 1656-1666. DOI: 10.1016/j.jnoncrysol.2012.04.036.

22. Meng, X., Huang, Y., Yu, H. \& Lv, Z. (2007). Thermal degradation kinetics of polyimide containing 2,6-benzobisoxazole units. Polym. Deg. Stabil. 92, 962-967. DOI: 10.1016/j. polymdegradstab.2007.03.005.

23. Vasconcelos, G. da C., Mazur, R.L., Ribeiro, B., Botelho, E.C. \& Costa, M.L. (2014). Evaluation of Decomposition Kinetics of Poly (Ether-Ether-Ketone) by Thermogravimetric Analysis. Mater. Res. 17(1), 227-235. DOI: 10.1590/S151614392013005000202. 